\title{
Effects of health screening for adults with intellectual disability: a pooled analysis
}

\author{
Nicholas Lennox, Robert Ware, Chris Bain, Miriam Taylor Gomez, \\ and Sally-Ann Cooper
}

\begin{abstract}
Health screening has been shown to have beneficial effects on health outcomes in adults with intellectual disability. However, the nature of the population, which makes it difficult to recruit, has meant past studies have been relatively small and effect estimates unstable. This study conducted a pooled analysis of two randomised trials and one cohort study, containing a total of 795 participants. Use of a simple, low-cost screening tool produced substantial increases in health-promotion and disease-prevention activity, when compared with usual care.

Keywords

disability; general practitioners; intellectual; outcome assessment; mass screening.
\end{abstract}

\section{INTRODUCTION}

People with intellectual disability have much unrecognised disease and inadequate health promotion. ${ }^{1-3}$ Barriers to providing satisfactory health care include difficulties gaining access, short consultation times, and communication difficulties. ${ }^{4}$ Beneficial effects of health screening in adults with intellectual disability have been reported: ${ }^{5-7}$ however, recruitment in this population is difficult, ${ }^{4,8}$ and individual studies have been small and effect estimates unstable. This study has addressed this by conducting a pooled analysis to assess the overall benefits of health screening for adults with intellectual disability.

\section{METHOD}

The Medline, PsycINFO, EMBASE, and CINAHL databases were searched to identify studies from articles published between 1980 and 2009. The terms: 'intellectual disability', 'trial OR study OR control', 'adults', and 'short health screening OR health assessment' were used. To be included, the study population had to be adults with intellectual disability, include a prospective intervention with a comparison group, and have allocation occurring at GP level or higher, to guard against carry-over effects within general practice. Two randomised trials were found,,$^{6,7}$ and one cohort study. ${ }^{5}$ One study investigating the effect of repeated screens was excluded due to allocation occurring within general practice. $^{9}$

Original data were obtained from each included study. Post-intervention unadjusted 1-year cumulative incidence was calculated for all outcomes. A multi-level mixed-effects logistic regression was used to compute the odds ratios and 95\% confidence intervals of achieving a healthrelated event in the health-screening group compared to the usual care group, with adjustment for clustering and study.

\section{RESULTS}

Three studies were identified that met the research criteria. All study participants lived in the community. 


\section{How this fits in}

People with intellectual disability have much unrecognised disease, inadequate health screening, poor health, and relatively short life spans. Benefits of health screening, including increased short-term health-promotion and diseaseprevention activity have been reported, but individual studies have been small. Stronger evidence for health screening could contribute significantly to promoting good health in this population.
- Study 1: Cooper et al conducted a matched cohort study in 2002-2003 in Scotland. ${ }^{5}$ Participants who received the intervention were individually matched on age, sex, and ability with adults from the neighbouring locality. The health screen used was The C21 Health Check. ${ }^{10}$ Nurses extracted data from GP notes, then interviewed and examined participants before reviewing the findings with a GP to formulate recommendations.

- Study 2: Lennox et al conducted a cluster randomised controlled trial in 2000-2001 in Australia. ${ }^{6}$ Randomisation clusters were groups of participants who shared a residence or GP. The health screen used was the Comprehensive
Health Assessment Program (CHAP). Carers completed a health history, before the adult with intellectual disability visited their GP, who reviewed the history, performed an examination, and completed an action plan.

- Study 3: Lennox et al conducted a second trial (2 x 2 factorial) in 2004-2005. ${ }^{7}$ Randomisation clusters were groups of participants who shared a GP. Interventions were a CHAP health screen and a health diary. There was no interaction between interventions, so health outcomes among those screened were compared with those receiving usual care, ignoring whether they received a diary. In all studies, clinical outcomes were collected from medical records at 12 months postintervention. In studies 2 and 3 , data were extracted using the same variable definitions. Where these were compatible to those used in study 1 , data were pooled. A disease diagnosis was defined as new if it had not been noted previously in the GPs' records or specialists' letters. In studies 2 and 3 , data extractors were masked; in study 1 they were not.

The pooled analysis provided data on 407 adults assigned to receive health screening and 388 who received usual care. Fifty-eight per cent of

Table 1. Number (\%) of sensory deficits and health-promotion and diseaseprevention actions, with pooled odds ratios (OR) and $95 \%$ confidence intervals, and odds ratios for each included study.

\begin{tabular}{|c|c|c|c|c|c|c|}
\hline & $\begin{array}{l}\text { Health } \\
\text { screening } \\
(n=407)\end{array}$ & $\begin{array}{l}\text { No health } \\
\text { screening } \\
(n=388)\end{array}$ & $\begin{array}{cc}\text { OR } & \text { O } \\
(95 \% \mathrm{Cl}) & \end{array}$ & $\begin{array}{l}\text { OR; Cooper } \\
\qquad 2006^{5}\end{array}$ & $\begin{array}{l}\text { OR; Lennox } \\
2007^{6}\end{array}$ & $\begin{array}{l}\text { OR; Lennox } \\
2009^{7}\end{array}$ \\
\hline \multicolumn{7}{|l|}{ Sensory systems } \\
\hline Vision test performed ${ }^{a}$ & $80(22)$ & $22(7)$ & $4.2(2.3$ to 7.4$)$ & - & 5.0 & 3.2 \\
\hline Vision impairment detected & $36(9)$ & $15(4)$ & 2.5 (1.2 to 5.2$)$ & 2.3 & 6.7 & 1.6 \\
\hline Acuity corrected by glasses & $18(4)$ & $10(3)$ & $1.9(0.8$ to 4.8$)$ & 1.4 & $n / c$ & 5.4 \\
\hline Otoscopic exam ${ }^{\mathrm{a}}$ & $141(40)$ & $89(26)$ & 1.9 (1.3 to 2.9$)$ & - & 2.7 & 1.1 \\
\hline Hearing test ${ }^{a}$ & $51(14)$ & $6(2)$ & 10.8 (3.4 to 34.3 ) & - & 73.5 & 4.2 \\
\hline Hearing loss identified & $24(6)$ & $2(1)$ & $12.6(2.2$ to 71.0$)$ & 5.4 & $\mathrm{n} / \mathrm{c}$ & 6.1 \\
\hline \multicolumn{7}{|l|}{ Immunisations } \\
\hline $\begin{array}{l}\text { Tetanus/diphtheria } \\
\text { immunisation given }\end{array}$ & $86(21)$ & $22(6)$ & 3.8 (2.0 to 7.5$)$ & 1.7 & 15.7 & 1.9 \\
\hline Hepatitis B immunisation given & $64(16)$ & $18(5)$ & 8.5 (3.5 to 20.8$)$ & 6.1 & 6.1 & $n / c$ \\
\hline Influenza immunisation given & $213(52)$ & $172(44)$ & 1.7 (1.0 to 2.8$)$ & 2.2 & 1.2 & 1.8 \\
\hline \multicolumn{7}{|l|}{ Blood pressure and weight } \\
\hline Blood pressure checked ${ }^{a}$ & $188(53)$ & $158(47)$ & $1.4(0.8$ to 2.4$)$ & - & 1.7 & 1.1 \\
\hline Weight recorded ${ }^{\mathrm{a}}$ & $170(48)$ & $71(21)$ & $3.5(2.1$ to 6.0$)$ & - & 3.9 & 3.2 \\
\hline Obesity identified & $33(8)$ & $12(3)$ & 2.7 (1.3 to 5.6$)$ & 1.4 & 3.6 & 2.5 \\
\hline Management plan established ${ }^{\mathrm{b}}$ & $15(45)$ & $7(58)$ & $0.6(0.2$ to 2.4$)$ & $\mathrm{n} / \mathrm{c}$ & 2.1 & 0.5 \\
\hline \multicolumn{7}{|l|}{ Women's health } \\
\hline Papanicolaou smear performed ${ }^{\circ}$ & $17(11)$ & $6(3)$ & $3.3(1.1$ to 10.1$)$ & $n / c$ & 8.5 & 0.9 \\
\hline Breast examination $^{d}$ & $25(16)$ & $18(10)$ & $2.2(0.9$ to 5.0$)$ & $n / c$ & 2.7 & 1.4 \\
\hline Mammography performed ${ }^{e}$ & $8(33)$ & $3(11)$ & 3.3 (0.4 to 25.7$)$ & $n / c$ & 20.0 & $n / c$ \\
\hline
\end{tabular}

${ }^{a}$ Studies 2 and 3 only; no health screening $n=338$, health screening $n=357$. ${ }^{\circ}$ Denominator is number of individuals identified as obese. 'Women in the recommended age range only; no health screening $n=178$, health screening $n=156$. ${ }^{\circ}$ Women only; no health screening $n=180$, health screening $n=158$. 'Women in the recommended age range only; no health screening $n=27$, health screening $n=24 . n / c=$ not calculable as no events in one group. 


\begin{tabular}{|c|c|c|c|c|c|c|}
\hline & $\begin{array}{c}\text { Health } \\
\text { screening } \\
(n=407)\end{array}$ & $\begin{array}{l}\text { No health } \\
\text { screening } \\
(n=388)\end{array}$ & $\begin{array}{c}\text { OR } \\
(95 \% \mathrm{Cl}) \\
\end{array}$ & $\begin{array}{c}\text { OR; Cooper } \\
2006^{5} \\
\end{array}$ & $\begin{array}{l}\text { OR; Lennox } \\
2007^{6}\end{array}$ & $\begin{array}{c}\text { OR; Lennox } \\
2009^{7} \\
\end{array}$ \\
\hline \multicolumn{7}{|l|}{ Endocrine } \\
\hline Thyroid test performed & $94(23)$ & $61(16)$ & $1.6(1.0$ to 2.4$)$ & 1.6 & 1.8 & 1.0 \\
\hline Thyroid disease & $14(3)$ & $12(3)$ & $1.1(0.5$ to 2.7$)$ & $\mathrm{n} / \mathrm{c}$ & 0.5 & 1.5 \\
\hline Diabetes & $4(1)$ & $6(2)$ & 0.8 (0.2 to 3.8$)$ & $\mathrm{n} / \mathrm{c}$ & $n / c$ & 0.8 \\
\hline Osteoporosis investigation & $9(2)$ & $3(1)$ & 2.9 (0.8 to 10.8$)$ & $\mathrm{n} / \mathrm{c}$ & 3.8 & 1.5 \\
\hline Osteoporosis & $2(0)$ & $4(1)$ & 0.5 (0.1 to 2.6$)$ & $\mathrm{n} / \mathrm{c}$ & $\mathrm{n} / \mathrm{c}$ & 0.6 \\
\hline \multicolumn{7}{|c|}{ Neuropsychiatric and behavioural } \\
\hline Psychiatric consultation & $46(11)$ & $43(11)$ & $1.0(0.7$ to 1.6$)$ & 2.3 & 0.9 & 0.7 \\
\hline Psychiatric disorder & $17(4)$ & $10(3)$ & $1.8(0.8$ to 4.0$)$ & 3.2 & $\mathrm{n} / \mathrm{c}$ & 0.6 \\
\hline Epilepsy & $8(2)$ & $8(2)$ & 0.9 (0.3 to 3.0$)$ & $\mathrm{n} / \mathrm{c}$ & $\mathrm{n} / \mathrm{c}$ & 0.2 \\
\hline Challenging behaviour & $11(3)$ & $13(3)$ & 0.8 (0.4 to 1.8$)$ & 3.1 & 1.2 & 0.3 \\
\hline \multicolumn{7}{|l|}{ Other systems } \\
\hline Hypertension & $7(2)$ & $3(1)$ & 2.4 (0.6 to 9.5$)$ & 6.7 & $n / c$ & $n / c$ \\
\hline Heart disease & $8(2)$ & $4(1)$ & $1.9(0.6$ to 6.5$)$ & $n / c$ & 0.9 & 1.9 \\
\hline Reflux disease & $13(3)$ & $7(2)$ & 1.9 (0.7 to 4.8$)$ & 4.6 & 3.8 & $n / c$ \\
\hline Constipation identified & $14(3)$ & $9(2)$ & $1.6(0.7$ to 3.9$)$ & 1.6 & 0.9 & 2.0 \\
\hline Skin neoplasm & $3(1)$ & $5(1)$ & $0.6(0.1$ to 2.4$)$ & $\mathrm{n} / \mathrm{c}$ & 0.5 & 0.3 \\
\hline Other diseases & $42(10)$ & $18(5)$ & 3.1 (1.6 to 6.1$)$ & 4.5 & 3.3 & 1.0 \\
\hline
\end{tabular}

$n / c=$ not calculable as no events in one group.

participants were male, $69 \%$ had mild or moderate intellectual disability, and the median age was 37 years (range 19-79 years). Overall, a greater proportion of males than females received health screening (55\% versus $47 \%)$; there was no difference in age or level of disability.

The intervention group generally received far more sensory testing and provision of healthpromotion or disease-prevention activities (Table 1). Notably, there were increases in vision (odds ratio $[\mathrm{OR}] 4.2 ; 95 \%$ confidence interval $[\mathrm{Cl}]=2.3$ to 7.4) and hearing (OR 10.8; 95\% Cl $=3.4$ to 34.3 ) tests performed and problems identified, as well as in key immunisations, obesity recording, and women's health screens. Typically, odds ratios varied by study, with wide and overlapping confidence intervals. For activities embedded in day-to-day practice, differences were less marked. Overall clinical activity and disease detection increased with screening, although neither notably nor significantly for most individual diseases (Table 2). No adverse effects from use of the screening tool were reported.

\section{DISCUSSION}

\section{Summary of main findings}

Participants who received health screening experienced substantial increases in clinical activities conducive to beneficial health outcomes. This occurred even though the screen was applied as a 'one-off' process, with no other changes in health provision. Most of these changes are just intermediate steps towards better health, and it is not possible to say adults with intellectual disability will consequently achieve better health over their life course. Nevertheless, the trend to improved healthcare practice suggests health screens are likely to provide real benefit. Repeated screens are likely to magnify benefits. ${ }^{9}$

\section{Strengths and limitations of the study}

Heterogeneity of results is probably largely due to chance: the two larger studies were conducted by the same team, the major difference being participants' accommodation setting. The study by Cooper and colleagues involved more intensive intervention, which may have led to the increases in new diagnoses for some diseases. ${ }^{5}$ There is unlikely to be any bias due to differential attrition, as follow-up rates were excellent, and randomisation and matching limit problems of confounding. These results are likely to be generalisable to a wide range of adults with intellectual disability in high-income countries, as study participants are quite representative of such populations.

\section{Implications for clinical practice}

In clinical practice, the use of a simple, low-cost, screening tool has obvious appeal, although to minimise time commitments these tools may require multidisciplinary support. It is likely that specific mental health screening would identify more neuropsychiatric and behavioural problems. Within 
the UK and Australia, there have been policy initiatives to promote health screening in this population through extra reimbursements to GPs. Although it is clear that health-screening tools have a significant short-term benefit in this population, examination of their long-term value is required.

\section{Discuss this article}

Contribute and read comments about this article on the Discussion Forum: http://www.rcgp.org.uk/bjgp-discuss

\section{REFERENCES}

1. Beange H, Lennox N, Parmenter T. Health targets for people with an intellectual disability. J Intellect Dev Disabil 1999; 24(4): 283-297.

2. Emerson E, Durvasula S. Health inequalities and people with intellectual disabilities: an introduction to the special issue. (editorial) J Appl Res Intellect Disabil 2005; 18: 95-96.

3. Cooper S-A, Melville C, Morrison J. People with intellectual disabilities. BMJ 2004; 329(7463): 414-415.

4. Lennox N, Taylor M, Rey-Conde $\mathrm{T}$, et al. Beating the barriers: recruitment of people with intellectual disability to participate in research. J Intellect Disabil Res 2005; 49(4): 296-305.

5. Cooper S-A, Morrison J, Melville C, et al. Improving the health of people with intellectual disabilities: Outcomes of a health screening programme after 1 year. J Intellect Disabil Res 2006; 50(9): 667-677.

6. Lennox N, Bain C, Rey-Conde T, et al. Effects of a comprehensive health assessment programme for Australian adults with intellectual disability: a cluster randomized trial. Int J Epidemiol 2007; 36(1): 139-146.

7. Lennox N, Bain C, Rey-Conde T, et al. Cluster randomized controlled trial of a tailored intervention to improve health for adults with intellectual disability who live in private dwellings. J Appl Res Intellect Disabil 2010; 23(4): 303-311.

8. Oliver PC, Piachaud J, Done J, et al. Difficulties in conducting a randomized controlled trial of health service interventions in intellectual disability: implications for evidence-based practice. J Intellect Disabil Res 2002; 46(4): 340-345.

9. Felce D, Baxter H, Lowe $\mathrm{K}$, et al. The impact of repeated health checks for adults with intellectual disabilities. J Appl Res Intellect Disabil 2008; 21(6): 585-596.

10. Glasgow University Centre for Excellence in Development and Disabilities (UCEDD). The C21st health check, version II. Glasgow: UCEDD, 2006. 